\title{
Rememorização: a constituição identitária do sujeito em "Era aqui", de Luiz Vilela
}

\author{
Eloiza Fernanda Marani \\ Universidade Federal de Mato Grosso do Sul (UFMS), Três Lagoas, \\ Mato Grosso do Sul, Brasil \\ elo marani@hotmail.com \\ https://orcid.org/0000-0003-1848-4819
}

DOI: http://dx.doi.org/10.21165/el.v47i3.1943

\begin{abstract}
Resumo
De acordo com os estudos sobre memórias e lembranças, observamos que todo indivíduo é fruto de acontecimentos do pretérito e resgata essa essência através da revisitação ao passado pelo mecanismo memorialístico. Nesse sentido, a produção literária contemporânea nos tem sido generosa no que tange à possibilidade de exploração analítica da configuração identitária do ser - personagem - através do passado, identificando o presente e caracterizando o futuro. Frente à composição memorialística, o indivíduo é revelado por meio das configurações espaciais, como vislumbraremos no conto "Era aqui", pertencente à coletânea Você verá (2013), de Luiz Vilela. Assim, sob a égide dos estudos narratológicos, teorias do conto sob o olhar de Piglia (2004), e debates de Bosi (1995) e Halbwachs (2006) sobre a memória, propomos uma análise procurando investigar como a rememoração do eu-passado contribui para a formação do eu-presente e projeta o eu-futuro na configuração da personagem protagonista deste conto.
\end{abstract}

Palavras-chave: literatura brasileira contemporânea; memória; identidade.

Remembrance: the identity constitution of the subject in "Era aqui", by Luiz Vilela

\begin{abstract}
According to the studies about memories and remembrances, we observe that every man is fruit of past events, and rescues that essence through the past revisitation by the memorialistic mechanism. In this sense, contemporary literary production has been generous in what concerns the possibility of analytical exploration of the identity configuration of being - character - through the past, identifying the present and characterizing the future. In front of the memorialistic composition, the individual is revealed by the spatial configurations, as we will see in the tale "Era aqui", from the collection of tales Você Verá (2013), by Luiz Vilela. Thus, under the aegis of narratological studies, the tale's theories under Piglia's perspective (2004), and Bosi's pleadings (1995) and Halbwachs (2006) about the memory, we propose an analysis looking for investigate the way that remembrance of self-past contributes to self-present formation and projects the self-future in the configuration of the main character of this tale.
\end{abstract}

Keywords: contemporary Brazilian literature; memory; identity.

\section{Introdução}

A literatura, de acordo com Antonio Candido (1995), possui um caráter humanizador, resgata, através da ficção, subjetividades do ser humano e o meio que o cerca, pois cada sujeito pode ser caracterizado pela ação do espaço em que habita. Dessa forma, temos na literatura uma forte contribuição na formação integral da identidade pessoal, pois somente a literatura possui o poder de conceituar, profundamente, a 
intimidade do ser humano, fornecendo a base cultural necessária ao indivíduo para viver plenamente a subjetividade integrada à sua vida prática.

Cada indivíduo é constituído por inúmeros momentos vivenciados no decorrer de seu caminho, os quais são guardados e resgatados pelo dispositivo da memória. Esses arquivos memorialísticos perfazem a identidade do sujeito que o possui e são, constantemente, destacados no trilhar da literatura, no intuito de explorar a essência do ser humano.

Temos memória como acepção da "capacidade de lembrar; recordação de algo passado; dispositivo que pode receber, conservar e restituir dados." (HOUAISS, 2011, p. 626), ou seja, uma ordem de intensa capacidade, um centro de registro, de armazenamento e de recuperação/recordação, em que cada pessoa, grupo, sociedade possuem "arquivados" determinados acontecimentos, arquitetando a criação de identidade.

Muitos são os estudos - principalmente de viés psicológico - que versam sobre a conceituação e designação da memória, enquanto fator biológico do humano. Entretanto, a assonância entre os estudos sobre a memória dá-se, significativamente, ao evento da constituição do ser presente, pela revisitação aos fatos pretéritos, pois todo sujeito é presentificado pelos atos vivenciados em um determinado tempo e, principalmente, espaço. A transposição da memória para o passado, muitas vezes, é alcançada através de espaços - físicos e/ou psicológicos - que funcionam como um start, resgatando certos sentimentos adormecidos e que são imprescindíveis para a constituição e solidificação da identidade do sujeito.

Frente a todos os debates, reflexões e conceitos que tangem o tema da memória, propomos uma leitura da constituição do indivíduo através da recordação espacial no conto "Era aqui", pertencente à coletânea de contos Você verá (2013), do escritor mineiro Luiz Vilela, o qual apresenta no cerne de suas obras o retrato, constante, dos percalços que constituem a essência do ser humano, com todos os acertos, erros, alegrias, tristezas e loucuras que circundam o caráter identitário do mesmo.

O autor nasceu em Ituiutaba, Minas Geral, em 31 de dezembro de 1942, estreou no cenário literário brasileiro aos 24 anos com o livro de contos Tremor de Terra (1967), o qual foi reconhecido e recebeu o Prêmio Nacional de Ficção em Brasília. Após a estreia e primeira premiação, diversas outras ocorreram, em 1973 recebeu o Prêmio Jabuti de melhor livro de contos com O fim de Tudo; em 2012, com o romance Perdição, recebeu o Prêmio Literário Nacional PEN Clube do Brasil; em 2014 recebeu da Academia Brasileira de Letras o Prêmio ABL de Ficção com o livro Você Verá; este último é detentor do conto apresentado neste estudo e indicia algumas das temáticas recorrentes na escrita do autor.

Para fomentar esta discussão, utilizamos como ferramenta de análise escritos que debatem sobre a memória e a lembrança, teóricos da narrativa e a teoria do conto de Ricardo Piglia (2004, p. 89), motivada na afirmação de que "todo conto conta duas histórias" e de que as interpretações podem ser apreendidas de diversos modos. 


\section{Memória como construção identitária}

A memória é o fio condutor que transporta a cultura pelos tempos, que permite a consciência de estarmos no presente e de já termos vivido um passado e que nos consente a noção do tempo, pois, por meio dela prosseguimos na linha de sucessões e de aprendizados que são compartilhados na ânsia de resguardar fatores imprescindíveis para a formação e revelação da essência humana.

O protagonista do conto "Era aqui" reconstitui seu passado no presente, por meio do dispositivo memorialístico. O conto, pertencente à coletânea Você verá (2013), apresenta como diegése a história do retorno de um homem, junto à sua namorada, ao interior, na cidade que cresceu e viveu a infância. Durante a narrativa, não há nomeação das personagens principais - o homem e sua namorada - , todavia, a linguagem bem estruturada contempla a ausência de nomes, sendo que a ênfase narratológica deste conto incide sob o espaço, detentor das lembranças e, consequentemente, da identidade do protagonista:

Ela balançou a cabeça em silêncio, um silêncio quase reverente - mas, é claro, não viu nada do que ele parecia estar vendo àquela hora em sua memória. Viu as árvores, os canteiros, os bancos da praça, como tinha visto antes as ruas, as casas e os edifícios. Estes, comparados com os da capital, onde moravam e onde ela nascera, não eram quase nada; mas, para uma cidade do interior como aquela, já eram muitos. (VILELA, 2013, p. 12, grifo nosso).

Toda trama narratológica é apresentada em uma praça, na qual antigamente situava-se um campinho de futebol onde o protagonista se divertia na infância. Na descrição, através da rememoração, o homem vai relatando a sua namorada as características do campinho de futebol, os embates políticos que circundavam aquele local, a alegria da infância, a satisfação de ter crescido em uma cidade interiorana, etc.

As praças são espaços livres públicos, com função de convívio social, inseridos na malha urbana como elemento organizador da circulação e de amenização pública, com área equivalente à da quadra, geralmente contendo expressiva cobertura vegetal, mobiliário lúdico, canteiros, bancos e, normalmente, ficam à frente da igreja matriz da cidade. A ideia de praça nos indica um espaço público, de ordem política, econômica, religiosa e militar, pois é cenário de múltiplas reflexões sobre temas que abordam a sociedade em geral. É comum encontrarmos características espaciais, voltadas a praças, como cerne das obras do mineiro Luiz Vilela, o qual aborda temáticas diversas, todavia, convergentes nas mesmas reflexões, como a do homem diante à sociedade moderna, a sexualidade, a solidão, a religião, etc.

No conto em análise, todo acontecimento do protagonista se dá num movimento de constituir o presente revisitando o passado, através do dispositivo espacial da praça, pois temos na memória um baú vivo e fluído de guardados, de imagens, de lembranças, de referências, onde está conservado o conhecimento construído de nossos ancestrais. Dessa forma, podemos afirmar que a constituição identitária do protagonista se dá de forma coletiva, ou seja, suas lembranças não são solitárias, apresentam-se somadas a atitudes e consequências de outras pessoas.

Com isso, podemos afirmar que as memórias não dizem respeito a apenas um indivíduo, mas, retomam agires do que foi vivido por nossos antepassados. É o que 
Halbwachs (2006, p. 39) vai chamar de memória coletiva, a memória que re-existe às experiências não só do indivíduo, mas do seu grupo:

Não basta reconstituir pedaço por pedaço a imagem de um acontecimento passado para obter uma lembrança. É preciso que esta reconstituição funcione a partir de dados ou de noções comuns que estejam em nosso espírito e também no dos outros, porque elas estão sempre passando destes para aqueles e vice-versa, o que será possível se somente tiverem feito e continuarem fazendo parte de uma mesma sociedade, de um mesmo grupo.

Para Halbwachs (2006), o indivíduo que lembra é sempre um indivíduo inserido e habitado por grupos de referência, em que a memória é sempre construída em grupo, mas é também, sempre, um trabalho do sujeito, ou seja, é coletivo sem deixar de ser subjetivo. Temos, portanto, um protagonista que se apropria das memórias - carregando em seu cerne lembranças e características de seus antepassados -, para recompor e reviver momentos marcantes da infância, momentos que são constituintes, no presente, da identidade da personagem.

Todos os anseios, angústias, dúvidas, revoltas, só são percebidos pelos leitores, através de uma voz que norteia toda a narrativa. Em "Era aqui", o narrador é quem organiza o discurso e direciona o olhar do leitor sobre a história narrada. Neste conto, segundo a definição de Genette (s/d, p. 244), o narrador apresenta-se como heterodiegético, um "narrador ausente da história que conta", que relata uma história a qual é estranho, uma vez que não integra nem integrou, como personagem, o universo diegético em questão. ${ }^{1}$

Tal narrador tende a adotar uma atitude demiúrgica dotado de uma autoridade que normalmente não é posta em causa, pois tem o poder de reger a perspectiva narrativa. Um exemplo é o fragmento no início do conto, "Adentrou então a alameda, calçada com pastilhas, e os dois foram, de mãos dadas, até o grande círculo central, quando ele novamente parou." (VILELA, 2013, p. 12).

Ao termos um narrador heterodiegético, percebemos que há uma narração em que, mesmo não participando da história, o narrador relata todos os detalhes espaciais e demonstra profundo conhecimento sobre os sentimentos das personagens. Dessa forma, temos uma narrativa em que a manipulação da diegése é feita pela voz do narrador, todavia, o foco narrativo incide sob o olhar do homem revisitando seu passado de forma quebrada, ora a lembrança se faz presente, ora se faz ausente.

A configuração memorialística da personagem principal é construída no decorrer da narrativa, de forma fragmentada, isto é, a seleção e disposição das imagens-lembranças vividas, ou a forma de organização interna de referências e memórias-hábitos, são apreendidas aos poucos pelo protagonista e por nós leitores:

- Um gol era lá, naquela ponta - mostrou, apontando com o dedo, de maneira tão incisiva, que o gol parecia ainda estar ali, no mesmo lugar, depois de todos aqueles anos. (VILELA, 2013, p. 12).

${ }^{1}$ GENETTE, Gerard. Voz. In: O discurso da narrativa. Tradução de Fernando Cabral Martins. Lisboa: Arcádia, s/d. p. 221-260. 
- O outro, o outro gol, era ali, perto daquela árvore, aquela árvore maior, aquela sibipiruna. (VILELA, 2013, p. 13).

- Era ali o gol - ele voltou a dizer. (VILELA, 2013, p. 13).

Este caráter fragmentário, em que o cenário é reconstituído e as lembranças são ativadas, traz como efeito de sentido a constituição deste sujeito, deste protagonista, que, assim como suas lembranças, também é um organismo que esteve e sempre estará organizando e selecionando fatos a serem vividos e relembrados.

No que diz respeito ao espaço, segundo Genette, há três aspectos distintos: o espaço, o ambiente e a ambientação. No conto em análise, o espaço físico é a praça, a qual se apresenta através das fotografias que perfazem as memórias do protagonista e que são relatadas conforme revivem em seu âmago. Já o ambiente - caracterizador das situações dramáticas suscetíveis ao espaço - abriga uma "atmosfera" de nostalgia e resiliência que perfazem a essência do protagonista no presente.

Como já relatado, a praça é fator primordial neste conto, é o espaço predominante nesta narrativa, em que a maior parte e mais significativa da história acontece. $O$ protagonista relata esse cenário com um teor de carinho, aconchego e saudosismo:

- Era aqui - ele disse, - era para aqui que o menino vinha quase toda tarde. Ele punha o calção, o gorro, pendurava o par de chuteiras no ombro e vinha. Aqui ele se encontrava com os companheiros e aqui ele corria, chutava, gritava ... (VILELA, 2013, p. 15).

Podemos vislumbrar o afago que o cenário descrito perpetua e resgata no protagonista, sentidos que estavam adormecidos e que são despertados pelo revisitar ao passado, no tempo e espaço, pois, as lembranças funcionam como pontes que constituem o mais íntimo da nossa essência e que completam nossa identidade. A personagem protagonista reconhece sua identidade de forma gradual, assim como o modo pelo qual o espaço é apresentado na narrativa, que, segundo Osman Lins, chama-se ambientação, é dado pouco a pouco pelo narrador durante o decorrer da história. Uma ambientação franca, composta por um narrador independente, que não participa da narração, mas a descreve de forma crescente, no propósito de configurar a personagem.

Dessa forma, temos a organização espacial ativada através das imagens memorialísticas do protagonista, o qual, estando no presente, volta-se ao passado para transformar em imagens a mensagem a ser transmitida, junto à emoção e às sensações que o acompanharam ou que são ressignificadas no momento presente:

- Ele começa lá, naquela ponta. Por que ele só começa lá, eu não sei. Talvez não fosse assim, na realidade, mas foi assim que ficou na minha memória. Ele começava lá. Aí vinha, rodopiando, e quando chegava aqui, ao meio, subia e se desfazia no ar. E aí a gente via umas folhinhas secas de árvore ou pedaços de papel despencando... (VILELA, 2013, p. 14).

É nítido o esforço que o protagonista do conto exerce para fazer vir à superfície o que estava imerso e oculto, movimento este que restringe o campo de indeterminação e a dúvida do sujeito, levando-o a retomar práticas consagradas, que de alguma forma o marcaram, pois a memória brota do embate entre a subjetividade do espírito e a exterioridade da matéria, que, por sua vez, se apresenta como cenário à emergência dessa lembrança. 
Para este protagonista, rememorar não se trata apenas de reviver o passado tal qual ele pudesse ter sido realizado, mas um esforço de reconstrução do passado diante das atuais possibilidades, em que o recordar e reviver se revelam pelo sentimento de angústia e revolta vivida na infância. Na passagem em que é relatada a destruição do campinho de futebol, fruto de diversos embates políticos e felicidade das crianças, percebemos um teor melancólico altíssimo, acompanhado pela revolta da execução de forma tão abrupta:

- Era uma tarde, uma tarde como essa, uma tarde de setembro. Eu nunca vou esquecer. Nós estávamos jogando, e aí, de repente, um caminhão veio entrando pelo campo e parou ali, perto do gol. Nós interrompemos o jogo e ficamos olhando. Dois caras desceram. Eles foram caminhando par o gol, e aí um deles, um gordo, mal-encarado, que estava com uma marreta na mão, disse qualquer coisa como "acabou a farra, meninada, pode ir pegando o caminho de casa". E aí ele começou a dar umas marretadas no travessão, para derrubálo. (VILELA, 2013, p. 15-16).

- E de repente, de repente aqueles retângulos mágicos, causa de tanta emoção, tanto entusiasmo, tanta alegria, eram apenas um punhado de paus amontoados no chão e depois atirados, com indiferença, à carroceria de um caminhão... (VILELA, 2013, p. 16).

A necessidade do reencontro com o espaço da infância e os fatos que o circundam são essenciais para o protagonista deste conto, pois é, exatamente, no momento de confronto sentimental e político que o nó narrativo se revela de forma complexa. Os sentimentos mal resolvidos que a demolição do campinho de futebol causou no protagonista são carregados até a fase adulta. Todavia, retomar esses momentos difíceis indica uma predisposição na reflexão e amadurecimento deste sujeito para, enfim, trilhar novos caminhos, sem esquecer-se das raízes e verdadeiras essências.

Ainda sobre a passagem da demolição do campinho de futebol, vislumbramos uma atmosfera triste, carregada de mágoas que, mesmo com o passar do tempo e o ganho da maturidade, ainda se faz presente nas memórias deste sujeito, “- O menino? O menino foi embora para casa. Foi embora e, quando lá chegou, fechou-se no quarto e chorou: chorou de dor, de raiva, de revolta por ver destruído, e daquela forma, algo que ele tanto amava..." (VILELA, 2013, p. 16).

Assim como vislumbramos, através da descrição da personagem protagonista, a transição do campinho de futebol para praça, também, surge de forma fragmentária à transição na essência deste indivíduo, com a revisitação de fatos pretéritos. A ação de externalizar sentimentos, vinculados a determinados espaços e/ou momentos, é necessária para a profunda e efetiva assimilação do fato ocorrido e, fundamentalmente, revela reflexões que se tornarão itinerários para a permanência no trilhar da vida.

$\mathrm{O}$ afeto emitido pelo protagonista sobre os momentos da infância, no presente, ganha uma nova direção, é transferido a sua namorada, companheira de histórias e vida, a qual, juntamente a seu amado, refaz o trajeto da infância, na ânsia da constituição identitária do portador destas lembranças. Assim sendo, na narrativa em questão, além da personagem protagonista, temos a presença de uma segunda personagem, a qual se apresenta com uma idade inferior à dele e portadora de uma personalidade sensível e suscetível, tentando acompanhar e apreender os relatos do namorado, como podemos notar nos trechos:

- Parece até que eu também estou vendo... (VILELA, 2013, p. 14). 
Ela fez um murmúrio, enquanto tentava, com a imaginação, participar daquelas lembranças, as lembranças de um homem bem mais velho do que ela, mas com quem sintonizava exatamente por aquele seu lado sensível, aquele seu lado... Não sabia bem como dizer. Sabia - isso, sim, ela sabia -, sabia que o amava, que gostava muito dele... (VILELA, 2013, p. 15).

O papel feminino é a figura que se esforça para comboiar e reviver os momentos ao lado do protagonista, com o propósito de manifestar apoio e aconchego em momentos decisivos na vida de seu amado:

[...] a mulher é mediadora e compreensível, traz a esperança de que novas gerações possam mudar o presente, melhorando-o. Essa esperança é simbolizada na declaração de amor do homem à companheira na sua última fala do conto. (SOUZA; AMARAL, 2015, p. 201).

Assim sendo, a interlocutora deste conto, a figura da mulher, assume a posição de auxiliar seu amado no trilhar de um futuro melhor e, ouvir relatos do passado na intenção de estabelecer uma reflexão da personagem protagonista, pois revisitar o pretérito, em um momento atual e reflexivo, resulta em presentificar e arquitetar um possível futuro.

No decorrer da narrativa, temos um fato que chama muita atenção, o canto do sabiá, que aparece na diegése mais de uma vez e que de início é percebido apenas pelo protagonista e, mais adiante, pela mulher:

Um sabiá, escondido na folhagem de uma árvore, emitia, a intervalos, o seu canto, sempre igual e sempre belo [...] Pensou em perguntar a ela se sabia que pássaro era aquele - para testar o seu conhecimento de bichos. Mas, por delicadeza, temendo que ela não fosse saber, não perguntou. (VILELA, 2013, p. 14).

As primeiras sombras da noite já vinham chegando - e o sabiá, incansável, continuava a cantar. [...] - Esse sabia está animado - ela disse. [...] Olhou, surpreso, para ela - e, num impulso, abraçou-a. (VILELA, 2013, p. 18).

Os pássaros, na cultura budista, simbolizam a comunicação além das barreiras do tempo, do espaço e do entendimento humano, uma ligação entre o humano e as divindades, entre a vida e a morte, entre a nobreza e o resto da humanidade, além de serem dotados de liberdade, leveza e delicadeza.

O canto do sabiá, reverberado na narrativa diversas vezes, simboliza o presságio de mudanças, esperança de novos tempos que irão surgir. Entretanto, a metamorfose de estágios e amadurecimentos, apenas se concretizará no reencontrar com o passado, vivido pelo protagonista, e que sugere o findar de uma etapa e o início de outra, pois, o "seguir em frente" só acontecerá devido às vivências do passado. Portanto, temos dois acontecimentos que nos levam a acreditar no começo de uma nova vida para o protagonista: o companheirismo e amor de sua namorada e o canto do sabiá, simbolizando esperança de um futuro melhor.

Toda a constituição memorialística, descrita e analisada neste conto, se opera no presente, sendo que é este tempo que oferece as condições necessárias para a sua formação. O tempo presente incentiva e prescreve a rememoração, atendendo às demandas de seu funcionamento social: 
A lembrança é uma imagem construída pelos materiais que estão, agora, à nossa disposição, no conjunto de representações que povoam nossa consciência atual. Por mais nítida que possa ser a lembrança de um fato antigo, ela não é a mesma imagem que experimentamos na infância, porque nós não somos os mesmos de então e porque nossa percepção alterou-se e, com ela, nossas ideias, nossos juízos de realidade e de valor. (BOSI, 1995, p. 55).

Ecléa Bosi nos alerta para um embate comum do nosso inconsciente, o paralelismo entre passado e presente. Enfaticamente, nos direciona a observar que a realização de escolhas no momento presente toma o passado como referência, avalia esse mesmo passado em favor da escolha atual, em que cada escolha anterior condiciona e influencia a escolha posterior. Contudo, as decisões que o homem adota, realizadas a partir de seu passado, só podem revelar-se de modo significativo no momento presente para, assim, coexistirem no reconhecimento da identidade mais própria e íntima ao sujeito.

Assim sendo, o universo que é reconstruído a partir da memória é o grande financiador do conto, em que a memória é exposta como uma personagem dentro da narrativa: ela permeia a narrativa, informa e emociona o espectador. Esse é transportado para uma época e para situações que habitam somente a memória da personagem protagonista, tendo o discurso manipulado pelo narrador.

Este homem, protagonista da narrativa, precisou se reencontrar com o passado, sua essência, para, enfim, voltar à civilização da cidade grande, ao lado de sua amada, e solidificar uma nova vida, todavia, sem deixar para trás toda bagagem de aprendizados que a infância lhe trouxe. Este "passo" a um novo começo é relatado no desfecho do conto:

- Acho que é bom a gente ir andando - disse. - Ainda temos de arrumar as nossas coisas no hotel, e até a saída do ônibus o tempo já não é mais tanto assim...

Eles se levantaram e foram, devagar, fazendo o caminho de volta.

Ao final da alameda, ele parou e voltou-se: teve vontade de fazer um gesto de despedida - despedida do velho campo, do menino e de um tempo que de havia muito e para sempre se fora -, mas achou que o gesto seria meio ridículo, e não fez. (VILELA, 2013, p. 18).

Ao findar da narrativa, assistimos o emoldurar-se completo de um sujeito em busca de identidade, acompanhado da mulher que o ama e que, possivelmente, caminhará ao seu lado no trilhar da vida. Todos os desdobramentos que a narrativa nos possibilita só são possíveis através do fator humanizador da literatura, em que o entendimento profundo e concreto apenas se dá na somatória de todos os fatores narratológicos no decorrer da diegése e, principalmente, uma leitura verticalizada e aguçada de suas composições, pois, de acordo com os estudos de Ricardo Piglia (2004), sabemos que toda narrativa abrange duas histórias, em que temos explicitamente a primeira história, totalmente revelada e, implicitamente, a segunda história, perfeitamente velada:

Trabalhar com duas histórias quer dizer trabalhar com dois sistemas diferentes de causalidade. Os mesmos acontecimentos entram simultaneamente em duas lógicas narrativas antagônicas. Os elementos essenciais de um conto têm dupla função e são empregados de maneira diferente em cada uma das duas histórias. Os pontos de interseção são o fundamento da construção. (PIGLIA, 2004, p. 90). 
Em "Era aqui", todo o topos oferece subsídio para que o protagonista da narrativa reaviva fatos importantes de seu passado, os quais configuram sua própria essência, pois voltar ao passado implica resgatar valores imprescindíveis ao ser humano, edificando a própria identidade, em que temos na "lembrança a sobrevivência do passado" (BOSI, 1995. p. 15). É por meio dela que o passado é recontado e perpetuado por esse protagonista e que suas reflexões e descobertas filosóficas se alicerçam.

Tomando por base que toda narrativa conta duas histórias, temos, portanto, na configuração da primeira história, do conto em análise, o relato das relações humanas, as injustiças sociais e políticas e os relacionamentos fartos de ausências sentimentais. Já como segunda história, vislumbramos a reflexão do homem, através da revisitação ao passado, enfrentando e descobrindo a verdadeira essência da sua identidade e, consequentemente, da vida. Todas as ponderações que envolvem as frustrações da segunda história são asseguradas pelo amor, sentimento que irá alavancar a personagem protagonista - juntamente com sua namorada - a um futuro promissor. Em uma leitura parecida, Rauer Ribeiro Rodrigues (2012, p. 131) estabelece associações entre as duas histórias:

\begin{abstract}
A primeira história é, pois, a história do desamor nas relações humanas, figurada na lembrança do homem em contraponto ao carinho vivido na vida íntima, e pública, com sua companheira. A segunda história é a de que o aconchego para as frustrações está no espaço amoroso - não se trata, aqui, de um espaço familiar, pois a criança que retorna para casa chora só, sem apoio à sua dor e frustração. É com o gorjeio do sabiá, reconhecido pela moça, que o homem tem a epifania do amor e, então, o casal se irmana, virando as costas para o passado da primeira história, a do desamor, das brigas políticas, do espaço público enxovalhado pela ação dos homens públicos. Se o sabiá, na literatura brasileira, é topos da saudade no exílio, em Luiz Vilela é o anunciador de tempos novos, nos quais a personagem se volta para ver o passado, mas percebe que é ridículo se despedir daquele brutal tempo antigo.
\end{abstract}

É revendo imagens, da história vivida e ouvida, que a personagem protagonista de "Era aqui" transmite ao outro, a namorada, o conhecimento construído por si na vivência, pois, "a memória permite a relação do corpo presente com o passado e, ao mesmo tempo, interfere no processo 'atual' das representações" (BOSI, 1995, p. 09), findando a importância do que fomos para o que somos agora e, para o que seremos no futuro. Sendo assim, a construção identitária mobiliza, necessariamente, o arsenal memorialístico do indivíduo, em que a busca memorial apresentará um viés identitário. Essa relação de mão dupla, no entanto, é marcada por conflitos entre o que deve ou não compor o processo memorial identitário do sujeito. Envolve, assim, o confronto e a escolha de versões do passado, para coexistirem no presente, configurando-se em meio a conflitos e tensões, pois:

Toda pessoa que tentar domesticar o passado irá, acima de tudo, apropriar-se dele, pois o incorpora e o marca com a sua impressão, como rótulo da memória manifestado nas histórias ou memórias da vida. Memórias na totalidade correspondem a identidades sólidas; a identidades fragmentadas, memórias dispersas. [...] a memória consolidada desfaz o sentimento de identidade.(CANDAU, 2006, p. 117, tradução nossa²).

\footnotetext{
${ }^{2}$ Toda persona que recuerda domestica el pasado pero, sobre todo, se apropia de él, lo incorpora y lo marca con su impronta, etiqueta de memoria manifiesta en los relatos o memorias de vida. A memorias totales le
} 
A partir das discussões apresentadas neste trabalho, podemos sugerir que o passado é domesticado porque é acessado somente sob a forma de um relato e, ao ser mediado pela linguagem, é impregnado pelas intenções do sujeito da rememoração, que apresenta em sua narrativa do passado a sua visão ou a sua versão do tempo atual.

Rememorar, portanto, é um trabalho empreendido para revisitar e revisar o passado, mas que está calcado no presente e por isso é também uma forma de revisar o agora. Dessa forma, narrar-se pode ser percebido como um trabalho de reler-se: ler novamente conferindo outros sentidos. Este é o ponto crucial da relação entre memória e identidade, pretendida na análise do conto "Era aqui" de Luiz Vilela, a qual ganha forma por meio do discurso, pois, para conferir significado ao tempo vivido e à bagagem de experiências do sujeito, é preciso dar forma a esse tempo.

\section{Considerações finais}

Aquilo que comprova a existência de um fato passado, que evidencia a existência da sucessão de dias em nossas vidas e ainda a ordem dos acontecimentos, recebe o nome de lembranças. Estas fazem parte de um dispositivo maior, a memória, utilizado para construir uma história, que guardam arquivos fundamentais da personalidade, da individualidade latente de cada ser humano, repleta de emoções e experiências, que resgatam a raiz de todos os sentidos, amores, ódios, medos e inquietudes.

$\mathrm{O}$ ato de reviver, rememorar é muito mais do que trazer o passado para o presente, trata-se de um instrumento para reavaliações, revisões, autoanálise, autoconhecimento e é por este caminho que a memória alcança a identidade, sendo fator chave para o encontro e reconstrução identitária. Dessa forma, memória e identidade se aliam ao discurso na medida em que ambas são construções discursivas, pois, narrando-se, o sujeito mobiliza um arsenal de experiências; põe em ação tudo o que o constitui para construir uma narrativa de si e consolidar-se como sujeito.

Em "Era aqui", conto de Luiz Vilela, a personagem protagonista ao reorganizar o passado por meio do discurso, seleciona algumas experiências e exclui outras, ganhando significância de momentos a serem apagados, modificados, distorcidos. Entretanto, outras experiências recebem destaque e são intensificadas, no intuito de se constituir um novo sujeito. Nesse processo, o sujeito da rememoração posiciona-se, por vezes, como alguém externo que relata, não apenas como protagonista, mas como testemunha dos fatos. Essa testemunha é o eu-presente olhando para o eu-passado e lendo-se com olhos atuais, que colorem o tempo vivido com a bagagem presentificada.

Todo o debate sobre a memória é, notoriamente, perceptível no conto em análise, em que há uma construção sobre o passado, atualizada e renovada no tempo presente, por um homem que busca encontrar e solidificar sua essência, sua identidade. Assim, a ficção de Luiz Vilela atende com eficácia a importância da rememoração, através das lembranças, evocando o passado como substrato, como forma de salvar o tempo do esquecimento e da perda.

corresponden identidades sólidas; a identidades fragmentarias, memorias dispersas. [...] la memoria consolida o deshace el sentimiento de identidad. 


\section{REFERÊNCIAS}

BOSI, E. Memórias e sociedade - lembrança de velhos. 3. ed. São Paulo: Companhia das Letras, 1995.

CANDIDO, A. O direito a literatura. In: . Vários Escritos. São Paulo: Duas Cidades, 1995.

CANDAU, J. Antropología de la memória. Tradução de Paula Mahler. Buenos Aires: Nueva Visión, 2006.

FRANCO JR., A. Operadores de leitura da narrativa. In: BONNICI, T. et al. Teoria literária: abordagens históricas e tendências. 3. ed. Maringá: Eduem, 2009.

FRIEDMAN, N. O ponto de vista na ficção: o desenvolvimento de um conceito crítico. Tradução de Fábio Fonseca de Melo. Revista USP, São Paulo, n. 53, p. 166-182, mar./maio 2002.

GENETTE, G. O discurso da narrativa. Tradução de Fernando Cabral Martins. Lisboa: Arcádia, s/d.

HALBWACHS, M. A memória Coletiva. São Paulo: Centauro. 2006.

HOUAISS, A.; VILLAR, M. de S. Dicionário Houaiss da língua portuguesa. Rio de Janeiro: Objetiva, 2009.

LEITE, L. C. M. L. O foco narrativo. São Paulo: Ática, 2002.

LINS, O. Lima Barreto e o espaço romanesco. São Paulo: Ática, 1976.

PIGLIA. R. Formas breves. Tradução de José Marcos Mariani de Macedo. São Paulo: Companhia das Letras, 2004.

RODRIGUES, R. R. Era aqui, ficção e sociedade em um conto de Luiz Vilela. Revista Alēre, UFMT, Tangará da Serra, v. 6, n. 6, p. 123-134, dez. 2012.

SOUZA, E. P. de; AMARAL, P. O tema da evasão nos contos de Luiz Vilela. Letras \& Letras, Uberlândia, v. 31, n. 1, p. 187-205, jan./jun. 2015.

VILELA, L. Você verá. São Paulo: Record, 2013.

Recebido em: 29/08/2017

Aprovado em: 13/11/2017 